\title{
FRAMEWORK FOR THE EVALUATION OF THE QUALITY OF PEDESTRIAN ROUTES FOR THE SUSTAINABILITY OF PORT-CITY SHARED AREAS
}

\author{
MATTEO IGNACCOLO, GIUSEPPE INTURRI, ELENA COCUZZA, \\ NADIA GIUFFRIDA \& VINCENZA TORRISI \\ University of Catania, Italy
}

\begin{abstract}
In recent years, there have been several changes that deeply affected the port-city relationship, due to the evolution of maritime transports, traffic volumes and port infrastructures. Thanks to the expansion of the cruise and yachting sectors and the redevelopment of waterfront and port spaces, shared areas have assumed mixed functions and activities that are attractive for passengers/tourists but potentially also for other users, such as citizens. Often, the unplanned distribution of these heterogeneous functions and activities results in overlapping and intersecting flows of freights/passengers, with the generation of criticalities for vulnerable users. Commonly, each passenger/tourist, and generally more pedestrians, are independent decision-making units, and their route choices depend not only on their trip destination but also on the on the attractiveness of the existing activities, on the geometric characteristics of the path and, generally, on its Level of Service (LOS) and quality, contrary to freight routes, which are generally based on minimum generalized cost values. Thus, having a good non-motorized accessibility is a determining factor for port-city sustainable development. This paper focuses its attention on pedestrian flows in port-city areas and the construction of a methodological framework to evaluate nonmotorized accessibility. The framework analyses the quality of pedestrian displacements, both through the LOS and a utility measure, by taking advantage of Geographic Information System (GIS) tools. The methodology has been tested on the case study of Catania, a medium-sized city located in the south of Italy, whose port is located in an area that has a strategic role due to its proximity to the historic centre. The proposed framework can contribute to providing a guide to transport and urban planners, local and port authorities and decision-makers in port-city planning, identifying criticalities and solutions to enhance the non-motorized accessibility and sustainability of the port systems and urban areas.
\end{abstract}

Keywords: non-motorized accessibility, quality of pedestrian/bicycle flows, port/city relationship.

\section{INTRODUCTION}

Today ports can be considered the chance to implement new planning strategies at different scales: since the 1960s, many port cities dominate the urban planning sector, in terms of redevelopment, recovery and integration between areas with different land use.

Such new port configuration attracts important flows of people, linked to the cruise, recreational boating and tourism sectors and has to face new interactions between port areas and urban city. Recently, port's spaces, losing their original functions, have acquired a great potential for transformation, taking hold in sectors such as the tourist and cultural reception and becoming a unique opportunity to redevelop highly degraded or marginal areas. The port-city interface areas therefore represents the opportunity for a sustainable development of port systems in urban areas, reconciling both the needs of the city and the port, and making their coexistence possible.

The growing attention to sustainable development has underlined the importance of accessibility as a valid criterion for each of the three pillars of sustainability (economic growth, environmental quality and social equity), considering it a key concept in transport planning [1]-[3]. Therefore, it has a decisive role in the processes of planning relations 
between port systems and urban areas of context. Undoubtedly, the redevelopment of port and surrounding areas must also pass through more sustainable scenarios from the point of view of mobility [4], in line with European Union policies, enhancing accessibility, promoting pedestrian mobility and cycling.

Having good non-motorized accessibility is a determining factor for sustainable port-city development. Unlike goods, whose choice of route is dictated by the principle of generalized minimum cost, pedestrian mobility, especially in urban areas, does not need to favour a fast movement from an origin to a destination. Commonly, pedestrian's route choice depends, indeed, on the quality of the path and the attractiveness of existing activities and spaces along it. In this view, the aim of this study is to focus attention on non-motorized mobility in port-city areas and to provide a methodological framework to evaluate the quality of non-motorized paths, both in terms of flow and attractiveness of routes, in order to identify the main critical issues and possible solutions. Methodology has been applied to the case study of the Port of Catania and its relationship with the surrounding urban areas.

\section{LITERATURE REVIEW ON PEDESTRIAN ROUTE AUDIT}

Many studies on public transport have shown that walking is most natural and is the main mode for a person to access opportunities [6]-[8]. In this view, people should become more active in walking in open urban environments [9]. Thus, walkability, in turn, can be translated into a measure of how friendly the urban environment is to the pedestrian. Abley and Turner [10] consider sidewalks and crossings as two factors to determine if people feel well in an area suitable for walking. According to Loo and Lam [11], pedestrian safety, comfort, and convenience are three elements to be taken into consideration for walkability assessment. Hino et al. [12] have proposed in their study a broader view of the term walkability, combining three variables: diversified land use, high density residential and street connectivity. Frank et al. [5] have developed a Walkability Index, derived as a function of net residential density, retail floor area ratio, land use mix, and intersection density. Some indices are based on a weighted combination of built environment criteria [13]-[16]. Malavasi et al. [17] considered the type of residences, proximity of shops and commerce, perception of access to these places, the geometry of streets, facilities for walking and cycling and safety in relation to traffic and crime as variables. Reis et al. [18] examined the effect of income on walkability and the association with physical activity outcomes.

Recent studies have combined physical environment indicators into different indices (for example, Neighborhood Accessibility Index [19]; built environment index [20]; the 3Ds [21]) and tried to merge them with transportation or traffic data. Mixed land-use, street connectivity and high residential density as urban form indicators seem to be positively related to active transportation [5] and therefore were used to create an Aggregated Walkability-Index (AWI). In the study of Iacono et al. [22], it is interesting to note that conventional accessibility measures, both for pedestrian and cycling modes, consider impedance as a function of time and distance.

The Pedestrian Environment Review System - PERS [23] is a method for assessing the performance of urban environments for pedestrian and cycling mobility, developed by TPL (Transport Research Laboratory) and applied as a control tool for the pedestrian mobility system in the city center of London. This method involves filling in forms (comments and scores regarding a series of parameters). Subsequently, the data collection is processed by GIS software. It is a systematic process for evaluating the pedestrian environment and identifying those factors of fundamental importance for pedestrians in public spaces.

The Pedestrian Level of Service (LOS) [24] is a qualitative measure used to analyze roadways and intersections by categorizing traffic flow and assigning quality levels of traffic 
based on performance measure like vehicle speed, density, congestion, etc. The study of the pedestrian flow is carried out in analogy with the vehicular one, considering as quantitative measures the freedom to maintain desired pedestrian speed and overtake other pedestrians.

From this literature analysis it emerged that few studies focus on walkability and accessibility in the vicinity of port areas and on the way in which the correct geometry and pleasantness of pedestrian routes can affect port security for non-motorized users. In the next chapter, we present an approach to evaluate quality of non-motorized paths in proximity of port areas, based on LOS methodology and a measure of Utility [25].

\section{QUALITY OF PEDESTRIAN ROUTES IN PORT-CITY SHARED AREA: A METHODOLOGY FRAMEWORK}

\subsection{Pedestrian LOS according to the Highway Capacity Manual, 2010}

According to the Highway Capacity Manual (HCM) [24], the evaluation of the pedestrian path is carried out by firstly calculating the LOS Score of the facility, which is the sum of LOS Score of several segments ( $\mathrm{I}_{\mathrm{p}, \mathrm{seg}}$ ), formed by links and intersections (Fig. 1) For a complete description on how the equations are obtained please consult HCM 2010 [24].

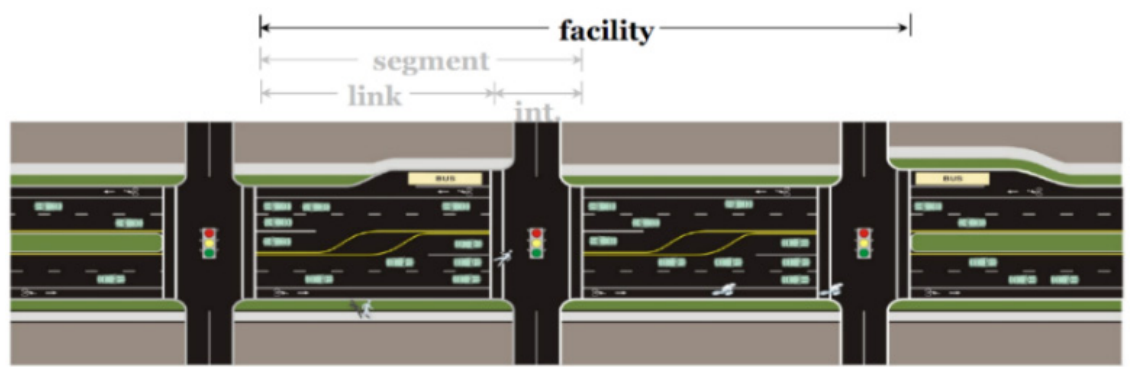

Figure 1: Pedestrian facility scheme. (Source: HCM, 2010 [24].)

For each part of the facility the LOS score is evaluated as follows:

$$
I_{p, l i n k}=6.0468+F_{v}+F_{S}+F_{w},
$$

where $F_{v}=$ Vehicle Volume Factor depending on the flow rate $(v e h / h)$ and the number of through lanes in direction of travel; $\mathrm{F}_{\mathrm{s}}=$ Vehicle Speed Factor, depending on car running speed $(\mathrm{mi} / \mathrm{h}) ; \mathrm{F}_{\mathrm{w}}=$ Cross-Section Factor, depending on the geometric parameters of the street

$$
I_{p, \text { int }}=0.5997+F_{w}+F_{S}+F_{\text {delay }}+F_{v},
$$

where $\mathrm{F}_{\mathrm{w}}=$ Cross-Section Factor, depending on number of traffic lanes crossed; $\mathrm{F}_{\mathrm{s}}=$ Speed Factor, depending on minor street traffic volume (veh/ln/15 $\mathrm{min}$ ) and minor street midblock auto speed $(\mathrm{mi} / \mathrm{h}) ; \mathrm{F}_{\mathrm{v}}=$ Vehicle Volume Factor, depending on: traffic flow over crosswalk (veh/h); number of right-turn channelizing island along crossing; traffic volume of the crossed street (veh/ln/15 min)

$$
I_{p, \text { seg }}=F_{c d}\left(0.318 I_{p, \text { link }}+0.220 I_{p, \text { int }}+1.606\right),
$$

where $\mathrm{F}_{\mathrm{cd}}=$ Crossing Difficulty factor depending on minimum of diversion time and unsignalized crossing delay time. 
The quality of the pedestrian flow is classified into six levels named with the letters "A" to "F", where with the "A" LOS pedestrian paths have low traffic volumes and wide protected sidewalks, while the "F" LOS pedestrian paths have high traffic volumes, narrow or absent sidewalks and with any protection from vehicles. To determine the LOS, one must calculate the average pedestrian space given by the relation:

$$
A_{p}=60 \frac{s_{p}}{v_{p}}
$$

where $S_{p}$ is crossing pedestrian speed and $v_{p}$ is the sidewalk pedestrian volume. Pedestrian LOS is finally evaluated by matching the LOS Score and the $A_{p}$ according to the matrix presented in Fig. 2.

\begin{tabular}{|l|l|l|l|l|l|l|}
\hline & \multicolumn{5}{|c|}{ LOS by Average Pedestrian Space $\left(\mathrm{ft}^{2} / \mathrm{p}\right)$} \\
\hline $\begin{array}{l}\text { Pedestrian } \\
\text { Los Score }\end{array}$ & $>60$ & $>40-60$ & $>24-40$ & $>15-24$ & $>8-15$ & $\leq 8$ \\
\hline$\leq 2$ & A & B & C & D & E & F \\
\hline$>2,00-2,75$ & B & B & C & D & E & $F$ \\
\hline$>2,75-3,50$ & C & C & C & D & E & F \\
\hline$>3,50-4,25$ & D & D & D & D & E & $F$ \\
\hline$>4,25-5,00$ & E & E & E & E & E & F \\
\hline$>5,00$ & F & F & F & F & F & $F$ \\
\hline
\end{tabular}

Figure 2: LOS by average pedestrian space.

However, the HCM carries out the study of pedestrian LOS in analogy with the vehicular one, considering the possibility for a pedestrian to walk at a desired speed as its pillar. Actually, the evaluation of a pedestrian path must also take into account the pleasantness of the route and therefore the presence of services and activities. Therefore, it is also very important to add a measure of the systematic utility associated to pedestrian routes, as performed in the next section.

\subsection{Utility of pedestrian path}

The evaluation of utility of a pedestrian path is based on the study conducted in 2004 by Ignaccolo and Caprì in 2004 [25], which considers the utility of each link depending on the linear combination of attractiveness parameters:

$$
u_{j}=\sum \beta_{x} \cdot P_{y}+u_{g i},
$$

where $\mathrm{P}_{\mathrm{y}}=$ number of activities (e.g. restaurants, monumental buildings, churches); $\beta_{x}=$ calibration coefficient; $u_{g i}=$ utility component associated to enjoyment of link $i$.

For each route the utility is given by the product of $\bar{u}_{a}=\left[\begin{array}{llll}u_{1} & u_{2} & \ldots & u_{n}\end{array}\right]=$ link utility vector ( $N=$ number of links) and $\bar{A}_{i}=$ incidence vector for route $i$ :

$$
U_{i}=\bar{u}_{a} \cdot \bar{A}_{i} .
$$

Finally, the method assigns to each route $i$ a "systematic utility" $V_{i}$ given by the difference between the Ui and a "disutility" in terms of distance:

$$
V_{i}=U_{i}-\beta_{d} \cdot f\left(L_{i}\right)
$$


where $f(\mathrm{Li})=$ non-utility function associated to the length of route $i ; \beta d=$ weight coefficient for length. The joint use of the two measures allow to take into account the geometric features of the route but also the present activities and its global pleasantness, which greatly affect the choice of the path in the context of non-motorized mobility.

\section{CASE STUDY: THE PORT OF CATANIA}

\subsection{Territorial framework}

The case study of this work is Catania, a coastal medium-sized city of about 300.000 inhabitants located in the south of Italy. It is part of a greater Metropolitan Area of about 750.000 inhabitants, which includes the main municipality and 26 surrounding urban centers [26], [27]. Catania develops along the Sicilian Ionian coast for a length of about $9 \mathrm{~km}, 2$ of which are characterized by the presence of the port. The relationship with the sea is unique and of great traditional, historical, cultural and environmental value. Nevertheless, it has been the subject of a wide debate for several years, being Catania awaiting a new General Urban Development Plan and the proposal for a Port Regulatory Plan (PRP), presented by the Port Authority in 2004. The Port of Catania according to the national classification is an international commercial seaport. In recent years there have been significant developments in containers and Ro-Ro and Ro-Pax ferries, thanks to its location and connection with the regional road and motorway network, with the airport and the Bicocca train station. The entire Ro-Ro and container traffic has recently been moved to the commercial new Darsena, located in the south area of the port and inaugurated in July 2015 (Fig. 2), for a total of 120,000 m2 with an increase of $70 \%$ of the current surface. Despite this delocalization of freight traffic in the southern area, the northern area is characterized by a mixed use of areas and infrastructures, due to the significant and continuous commercial growth of recent years. A direct consequence is the interference both of vehicle (i.e. private and freight traffic) and pedestrian flows and the absence of dedicated spaces and reserved paths for pedestrian and bicycle mobility. Recently, the access and exit of heavy vehicles is allowed through the Faro Biscari gate, located to the south and connected to the Service Axis, in order to minimize the interferences with congested urban traffic. The Dusmet gate, on the other hand, is dedicated for pedestrians and private vehicles. Therefore, at present, along the external perimeter of the port, as well as along the neighboring streets, it is possible to highlight a shortage of exclusively reserved areas for pedestrian and cycling mobility. Despite several proposals for redevelopment over time, the conditions of marginality and degradation that characterize the portion between the Faro Biscari and Piazza Borsellino are remaining.

\subsection{Data used and analysed scenarios}

For the application of the presented methodology the following input data have been used:

- Pedestrian network, data on pedestrian and traffic flows from the General Urban Traffic Plan of Catania (2013);

- a zonation in 14 zones of the study area (Fig. 3);

- a pedestrian travel speed of $3 \mathrm{ft} / \mathrm{s}$ has been assumed;

- an analysis area of about $1 \mathrm{~km}$ - radius has been examined, taking into account the distribution of activities, amenities and services and considering pedestrian paths consistent with a walkable distance. 


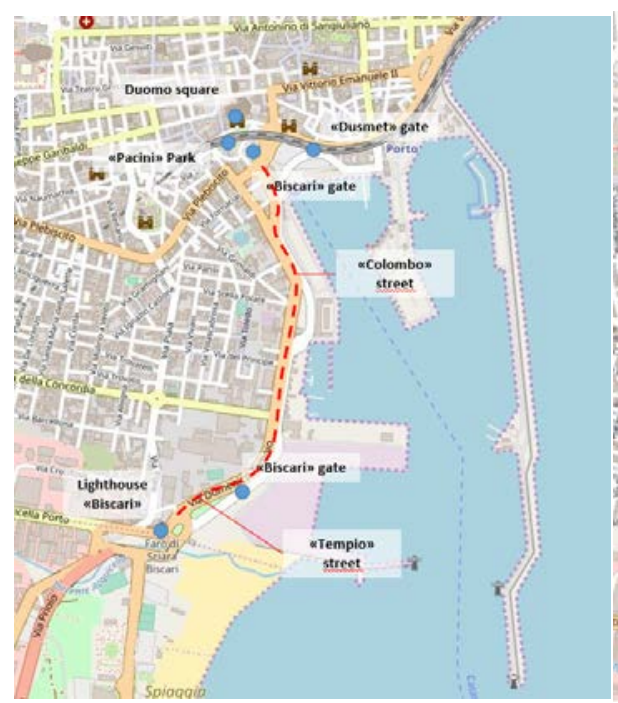

(a)

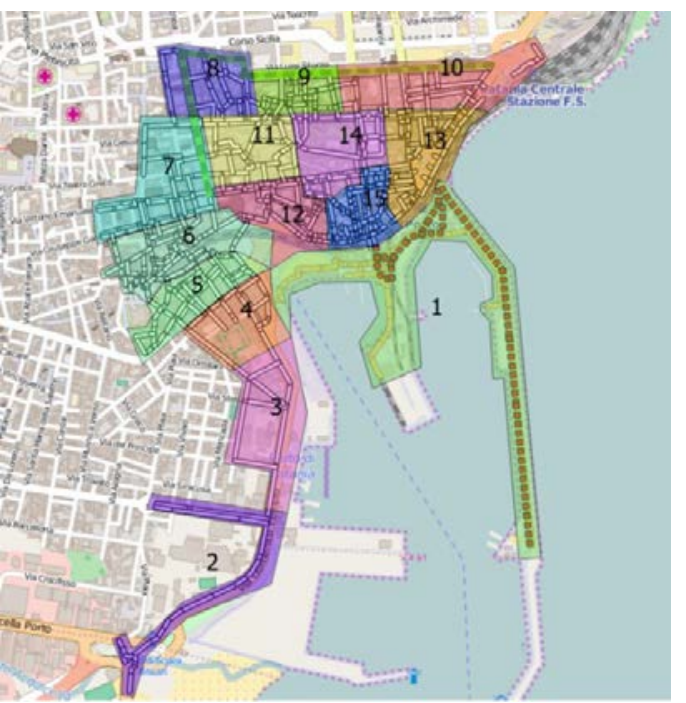

(b)

Figure 3: (a) Main points of interest; and (b) Zonation of the study area.

A mathematical model of the network model has been built within TransCAD, a software which combines a GIS and a set of transport models in one integrated environment. Pedestrian paths evaluation has been performed for two different scenarios:

1. Scenario 1 - Current situation, as described in Section 4.1;

2. Scenario 2-An alternative to the 2004 PRP proposal, describes in Section 4.3.2.

\subsection{Main results}

\subsubsection{Current situation}

Results of LOS and Utility levels for current situation are reported in Fig. 4. In zone 1, which coincides with port area, results show, as a consequence of the recent delocalization of the Container, Ro-Ro and Ro-Pax activities in the New Commercial Dock, good values of the pedestrian LOS, except for the arcs of the network where an overlap between heavy vehicles and private vehicles remains. While, with regard to utility measures, although some areas are of great environmental and landscape value, utility values are much lower than LOS ones: this is due to several factors including the absence of protected paths, poor quality of existing ones (e.g. poor pavement conditions), presence of several barriers and the scarcity of commercial activities. In the western port-city interface area (zones 2, 3 and 4), LOS values vary from good to excellent, except for some arcs along the Colombo street in which the sidewalk goes from narrowing to absent. The utility associated with streets is on average higher than inside the port, since there are paths of exclusive use for pedestrian mobility. These values are affected, however, by the conditions of marginality and degradation of the district as well as by the presence of the port's walls, which represents a significant visual barrier, and by the low number of commercial activities. In zone 4 there are higher utility values of some streets close to areas with a higher quality of the surrounding urban environment, also due to the presence of commercial activities. 

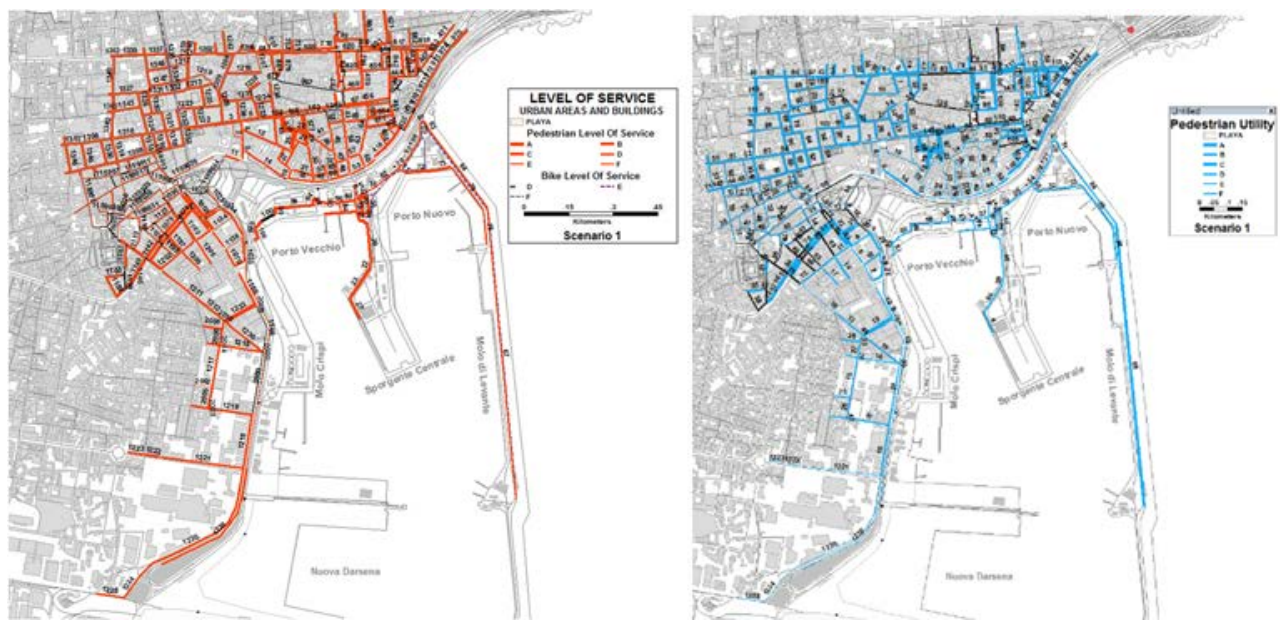

Figure 4: Pedestrian LOS and Utility in current situation. (Source: Cocuzza, 2017 [28].)

In zone 5 we have high values of both LOS and utility: we are already in the historical center of the city. Some streets, near the public transport terminal in Piazza Borsellino, have little value as they are affected both by the poor quality of the urban environment, where there is a high volumes of bus traffic, and by the presence of a public. Moreover, some secondary streets, characterized by a strongly degraded urban fabric and by the absence of sidewalks, have low values of LOS and utility. Zone 6 is the area where the historic fish market takes place in the morning and of high historical and monumental interest; however, the it suffers from a strong social decay and, except in the hours in which the market takes place, is quite dark and isolated. Getting close from zone 6 to port area, streets have high utility values, both for the quality of the surrounding urban environment (close to the main city square Piazza Duomo) and for the presence of various commercial activities, bars, restaurants and monuments.

Other streets, in correspondence with secondary roads due to the aforementioned degradation and the absence of sidewalks, have both low LOS and utility values. Zones 10 and 12 , full of commercial activities, have utility values more or less equal to 3 , while low LOS values due to the reduced sidewalk width, presence of obstacles, and high flows of twoway vehicular traffic affecting the road artery, which is the main axis of access from the south to the city. Moving away from port, those areas have high LOS but low Utility, due to a strong social and building degradation that involves the neighbouring streets. Finally, zones 7, 9 and 11, more distant from the port area and closer to the city centre, have high values both in terms of LOS and utility.

Following a careful examination of the results, it is possible to note that, in current situation, in the port-city interface areas as well as within the port, on average high levels of service are recorded; however, in the aforementioned areas, the corresponding utility values are almost always significantly lower, as a consequence of a poor degree of pleasantness of the pedestrian paths, of their architectural and/or environmental characteristics, of the low presence of attractive activities. It must be highlighted that the arcs most distant from the port area, where the urban space is well defined and the attractiveness present are well identified, have high values both in terms of service and utility. 


\subsubsection{Scenario 2 - Alternative 1 to the PRP Proposal of 2004}

In accordance with the Italian guidelines for the preparation of the Port Regulatory Plans of 2004, the proposal of Port Regulatory Plan, presented in 2004 by the Port Authority, identifies an area of interaction between port and city, called Waterfront, where other port facilities should be located but also urban activities linked to services, commerce, culture, administration, with the aim to connecting the fabric of the city with the most permeable port areas that are more compatible with pedestrian flows and urban activities.

The port infrastructures and the neighbouring areas in the north, closer to the historic centre, are intended for port activities (pleasure boating, fishing, public transport services by sea, cruise terminal and maritime station) which should be compatible with the urban uses envisaged by the guidelines; in addition, commercial activities and restaurant services, exhibition spaces, accommodation, catering, commercial, offices and public administrations are foreseen to be allocated in existing and project buildings. Furthermore, following the partial demolition of the customs walls, which runs for $1.4 \mathrm{~km}$ to delimit the operating area, approximately 420,000 square meters of areas currently within the port system would be made fully accessible by the city, with spaces and pedestrian/cycle paths and green areas, including a large public garden in to be integrated into the existing Villa Pacini (Fig. 5).

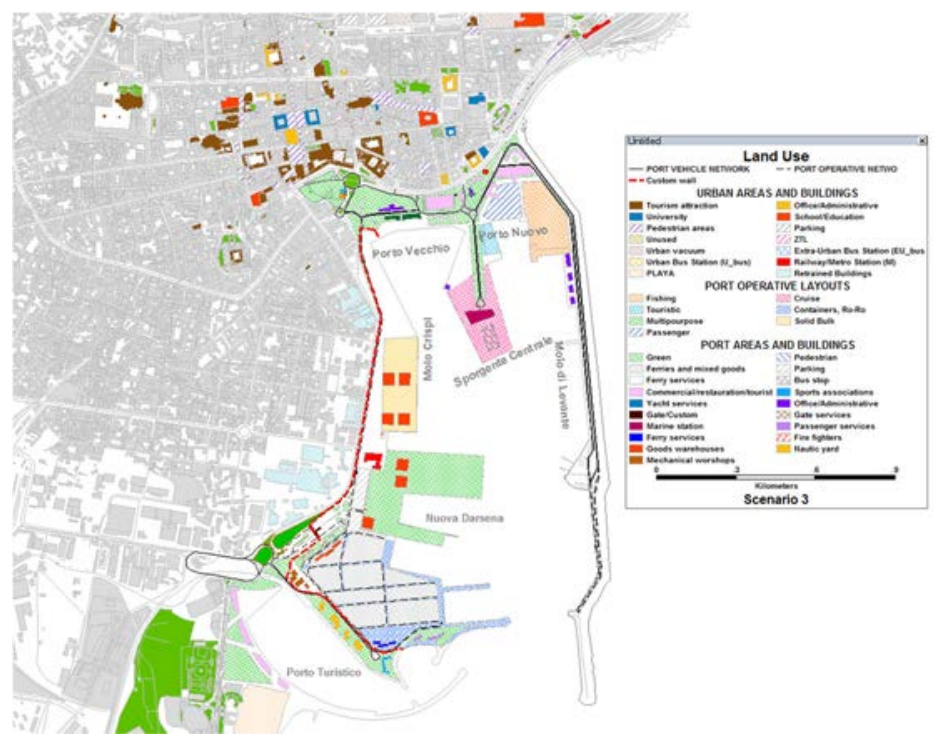

Figure 5: Land use planned. (Source: Cocuzza, 2017 [28].)

To solve the critical issues along the west road (zone 2 and 3), where no interaction between the port and the city is foreseen, it would be desirable to improve the usefulness of the paths for non-motorized mobility. The possible variant to the 2004 PRP proposal is to build a pedestrian and coastal cycle by taking advantage of the altitude difference, in part, between the urban road Colombo street and the port, moving back towards the sea the customs walls that would remain to separate the port operational area. A further integrative element would be the reconversion of buildings and abandoned areas along the aforementioned street to commercial, tourist and cultural activities (as well as to destinations 
linked to any infrastructural needs of existing and planned port activities) to redevelop the area plagued for years by marginal conditions and a strong social and building degradation.

Values of LOS and Utility have been calculated for a simulation of scenario 2, and results can be seen in Fig. 6.
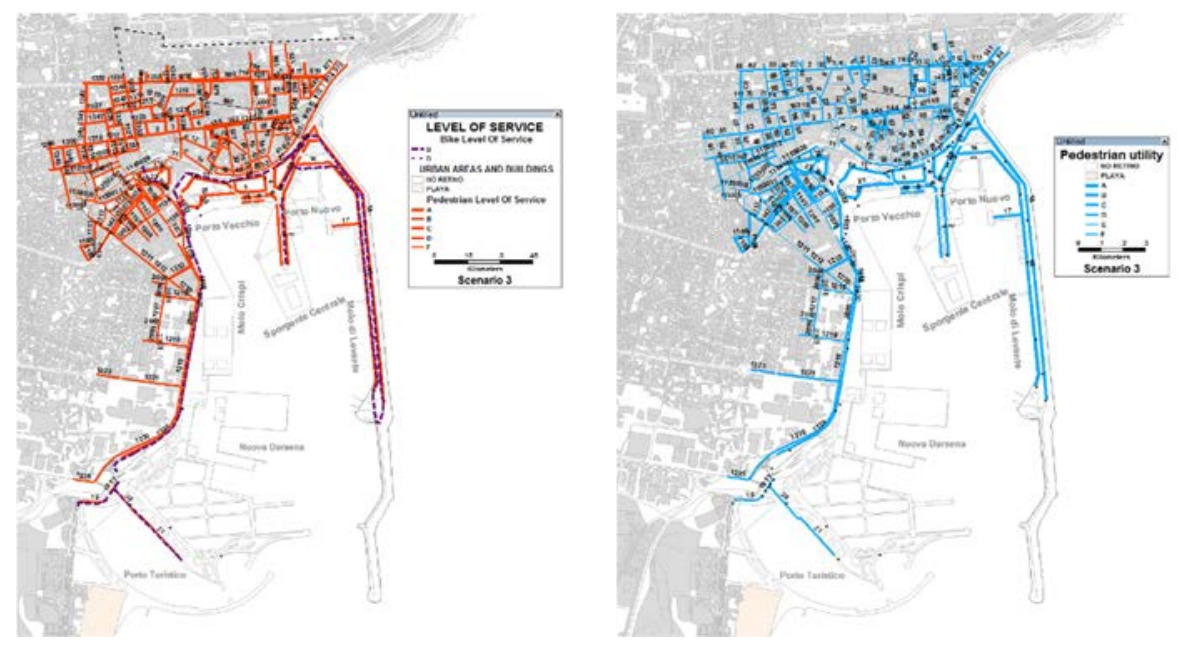

Figure 6: Pedestrian LOS and Utility in scenario 2. (Source: Cocuzza, 2017 [28].)

In the new Waterfront results show an improvement in LOS, due to new designed spaces and pedestrian paths. This solution would also involve a considerable increase in Utility values thanks to the clear definition of the spaces, especially those for the exclusive use of non-motorized mobility, to the planning of port and urban facilities, as well as to their distribution; moreover, around new equipped green areas are planned; finally, the demolition of the customs walls, which represents a visual barrier, would allow new grafts and urban views, aimed at connecting the fabric of the city with the most permeable port areas that are more compatible with urban flows and activities.

In zones 10 and 12, there is a general increase in utility while LOS values remain equal. This is mainly related to the persistence of critical issues, including those related to the high traffic flows along the artery.

From what has been said so far it can be seen that the possible opening and use of the northern area of the port would be a unique opportunity to create an urban waterfront and solve important critical issues related to both the non-motorized mobility and the lack of public facilities and green areas. An immediate benefit would be an increase in accessibility from the port to the historic centre, and vice versa, given the proximity of Piazza Duomo, both for tourists and citizens.

In zones 2, 3 and 4, following the improvement of pedestrian and cycle permeability and the interaction between the port and the city, results show a clear improvement of utility values. Furthermore, the creation of a route for the exclusive use of non-motorized mobility entails a positive increase in the LOS of some streets which previously lacked of such facilities. A comparison between the results obtained for LOS and Utility measures in the two different scenarios can be done through histograms that correlate Los and Utility with the two indices normalized on a scale ranging from 1 to 6 ( 1 worst value, 6 best value). An example for zone 3 is shown in Figs 7 and 8. 


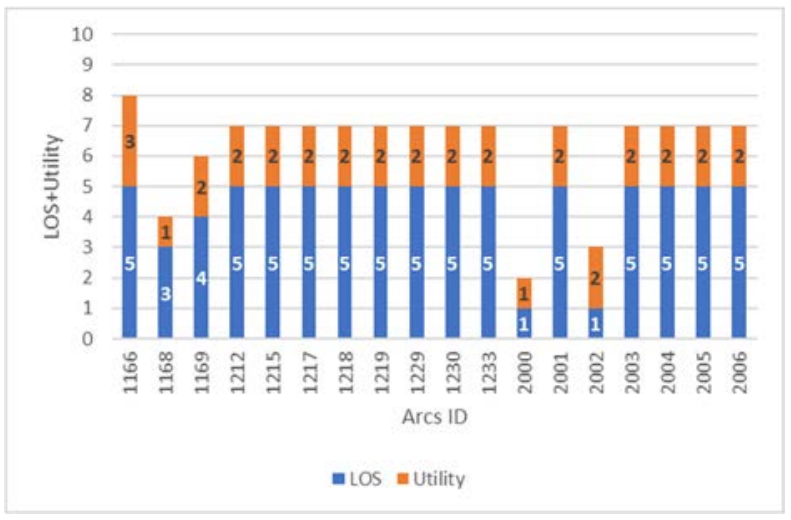

Figure 7: Histograms of zone 3 in current situation. (Source: Cocuzza, 2017 [28].)

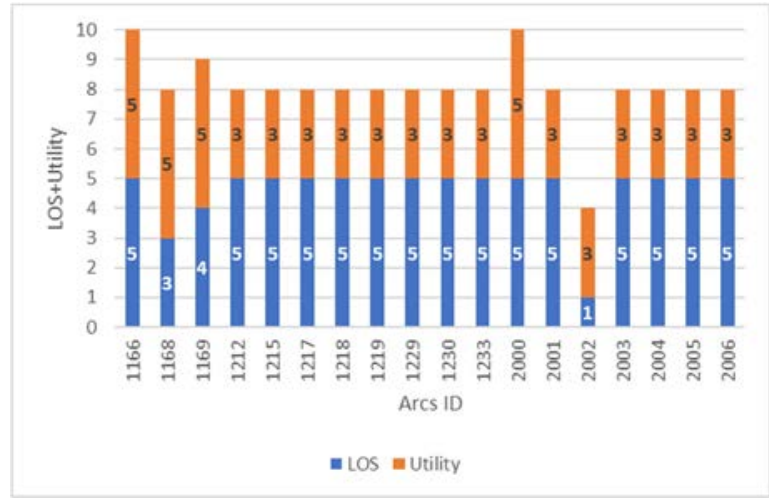

Figure 8: Histograms of zone 3 in scenario 2. (Source: Cocuzza, 2017 [28].)

Therefore a priority objective, for a greater integration between port and city and the search for new opportunities for sustainable growth, is to pursue the recovery and use of the tangible and intangible heritage, favouring the integration between the consolidated urban fabric and the sea, in addition to that through the usability of the port area with direct physical and visual access in the northern area, also through the redevelopment of the abandoned buildings along the via Colombo and via Tempio, to be used for new functions.

\section{CONCLUSIONS}

As often happened in different contexts in Italy and abroad, the consistent demand for the transport of goods and people in recent decades and the consequent unplanned distribution of heterogeneous functions and activities that over time have developed functions overlapping, has created heavily degraded or marginal zones close to port areas, with serious problems in terms of non-motorized accessibility and environmental impact.

From the study conducted on the existing literature, it emerged that the main performance measures of urban environments for non-motorized mobility can be traced to accessibility, level of service and utility measures. From the analysis of the results following the evaluation of the quality of non-motorized paths in two different scenarios of the case study, it is possible 
to argue that, in the current scenario, high LOS values do not correspond to equal utility values and improvements should be studied in order to increase both the correctness of the design and the amenity and pleasantness of non-motorized paths. The proposal of second scenario, combining elements of design and redevelopment of the adjacent port and city areas, allows an overall increase in the two indices and guarantees greater usability of the port and its surroundings by non-motorized users.

\section{REFERENCES}

[1] Giuffrida, N., Ignaccolo, M., Inturri, G., Rofè, Y. \& Calabrò, G., Investigating the correlation between transportation social need and accessibility: The case of Catania. Transportation Research Procedia, 27, pp. 816-823, 2017.

[2] Giuffrida, N., Le Pira, M., Inturri, G. \& Ignaccolo, M., Mapping with stakeholders: An overview of public participatory GIS and VGI in transport decision-making. ISPRS International Journal of Geo-Information, 8(4), p. 198, 2019.

[3] Inturri, G., Ignaccolo, M., Le Pira, M., Caprì, S. \& Giuffrida, N., Influence of accessibility, land use and transport policies on the transport energy dependence of a city. Transportation Research Procedia, 25, pp. 3273-3285, 2017.

[4] Banister, D., The sustainable mobility paradigm. Transport Policy, 15(2), pp. 73-80, 2008.

[5] Frank, L.D. et al., The development of a walkability index: Application to the neighborhood quality of life study. British Journal of Sports Medicine, 44, pp. 924 933.

[6] Din, M.A.M., Karim, M.R. \& Saritha, P., The aspect of walking accessibility in the development of GIS-based transit system modelling in Kuala Lumpur. Presented at 24th International Cartographic Conference, Santiago de Chile, Chile, 2009.

[7] Barr, A. et al., Associations of public transport accessibility with walking, obesity, metabolic syndrome and diabetes. Journal of Transport Health, 3(2), pp. 141-153, 2016.

[8] Boulange, C., Gunn, L., Giles-Corti, B., Mavoa, S., Pettit, C. \& Badland, H., Examining associations between urban design attributes and transport mode choice for walking, cycling, public transport and private motor vehicle trips. Journal of Transport Health, 6, pp. 155-166, 2017.

[9] Moura, F., Cambra, P. \& Gonalves, A., Measuring walkability for distinct pedestrian groups with a participatory assessment method: a case study in Lisbon. Landscape and Urban Planning, 157, pp. 282-296, 2017.

[10] Abley, S. \& Turner, S., Predicting walkability. Transport Agency research report 452, 2011.

[11] Loo, B. \& Lam, W., Geographic accessibility around elderly health care facilities in Hong Kong: a micro-scale walkability assessment. Environment and Planning B: Planning and Design, 39(4), pp. 629-646, 2012.

[12] Hino, A.A.F., Reis, R.S. \& Florindo, A.A., Built environment and physical activity: A brief review of evaluation methods. Revista Brasileira de Cineantropometria Desempenho Humano, 12(5), 2010.

[13] Berrigan, D., Pickle, L.W. \& Dill, J., Associations between street connectivity and active transportation. International Journal of Health Geographics, 9(1), 2010.

[14] Gori, S., Nigro, M. \& Petrelli, M., Walkability indicators for pedestrian-friendly design. Transportation Research Record: Journal of the Transportation Research Board, pp. 38-45, 2014. 
[15] Habibian, M. \& Hosseinzadeh, A., Walkability index across trip purposes. Sustainable Cities and Society, 42, pp. 216-225, 2018.

[16] Mahdi, A., Mehdi, M., Muhammad, Z.S., Zohreh, A.S. \& Mehdi, A.K., Evaluating the capability of walkability audit tools for assessing sidewalks. Sustainable Cities and Society, 37, pp. 475-484, 2018.

[17] Malavasi, L.M., Duarte, M.F.S., Both, J. \& Reis, R.S., Neighborhood walkability scale (news - Brazilian version): validity and reliability. Revista Brasileira de Cineantropometria Desempenho Humano, 8(3), p. 107, 2006.

[18] Reis, R.S., Hino, A.A.F., Rech, C.R., Kerr, J. \& Hallal, P.C., Walkability and physical activity: Findings from curitiba Brazil. American Journal of Preventive Medicine, 45(3), pp. 269-275, 2013.

[19] Krizek, K.J., Operationalizing neighborhood accessibility for land-use-travel behavior research and regional modeling. Journal of Planning Education and Research, 22, pp. 270-287, 2003.

[20] An easy to compute index for identifying built environments that support walking. http://web.utk.edu/ tnmug08/TRB/ped.pdf. Accessed on: 29 May 2014.

[21] Cervero, R. \& Kockelman, K., Travel demand and the 3Ds: Density, diversity, and design. Transportation Research Part D, 2, pp. 199-219, 1997.

[22] Iacono, M., Krizek, K. \& El-Geneidy, A., Measuring non-motorized accessibility: Issues, alternatives, and execution. Journal of Transport Geography, 18, pp. 133-140, 2010.

[23] Allen, D. \& Spencer, C., New directions in street auditing: lessons from the PERS audits. Presented at 8th International Conference on Walking and Liveable Communities, Toronto, Canada, 2007.

[24] TRB, Highway Capacity Manual, National Research Council: Washington, DC, 2010.

[25] Ignaccolo, M. \& Caprì, S., Pedestrian accessibility and mobility within the island of Ortigia, Siracusa. Conference Proceedings of the VII International Conference: Living and Walking in Cities, 2004.

[26] Torrisi, V., Ignaccolo, M. \& Inturri, G., Innovative transport systems to promote sustainable mobility: Developing the model architecture of a traffic control and supervisor system. Lecture Notes in Computer Science (including subseries Lecture Notes in Artificial Intelligence and Lecture Notes in Bioinformatics), 10962 LNCS, pp. 622-638, 2018.

[27] Torrisi, V., Ignaccolo, M. \& Inturri, G., Toward a sustainable mobility through a dynamic real-time traffic monitoring, estimation and forecasting system: The RE.S.E.T. project. Town and Infrastructure Planning for Safety and Urban Quality: Proceedings of the XXIII International Conference on Living and Walking in Cities (LWC 2017), p. 241, 2018.

[28] Cocuzza, E., Sostenibilità dei Sistemi Portuali dn Ambito Urbano. Valutazione dell'accessibilità non Motorizzata nelle Aree di Interfaccia Porto/Città. PhD thesis, University of Catania, 2017. http://dspace.unict.it/handle/10761/3812. Accessed on 20 May 2019. 